\title{
Cholesteryl ester transfer-protein modulator and inhibitors and their potential for the treatment of cardiovascular diseases
}

This article was published in the following Dove Press journal:

Vascular Health and Risk Management

17 May 2012

Number of times this article has been viewed

\author{
Hisashi Shinkai \\ Central Pharmaceutical Research \\ Institute, JT Inc, Osaka, Japan
}

Correspondence: Hisashi Shinkai Central Pharmaceutical Research Institute, JT Inc, I-I Murasaki-cho, Takatsuki, Osaka, 569-I I25, Japan $\mathrm{Tel}+8|7268| 9700$

Fax +8172 68I 9725

Email hisashi.shinkai@jt.com
Abstract: Elevated low-density lipoprotein (LDL) cholesterol and lowered high-density lipoprotein (HDL) cholesterol are important risk factors for cardiovascular disease. Accordingly, raising HDL cholesterol induced by cholesteryl ester transfer protein (CETP) inhibition is an attractive approach for reducing the residual risk of cardiovascular events that persist in many patients receiving low-density LDL cholesterol-lowering therapy with statins. The development of torcetrapib, a CETP inhibitor, was terminated due to its adverse cardiovascular effects. These adverse effects did not influence the mechanism of CETP inhibition, but affected the molecule itself. Therefore a CETP modulator, dalcetrapib, and a CETP inhibitor, anacetrapib, are in Phase III of clinical trials to evaluate their effects on cardiovascular outcomes. In the dal-VESSEL (dalcetrapib Phase IIb endothelial function study) and the dal-PLAQUE (safety and efficacy of dalcetrapib on atherosclerotic disease using novel non-invasive multimodality imaging) clinical studies, dalcetrapib reduced CETP activity by $50 \%$ and increased HDL cholesterol levels by $31 \%$ without changing LDL cholesterol levels. Moreover, dalcetrapib was associated with a reduction in carotid vessel-wall inflammation at 6 months, as well as a reduced vessel-wall area at 24 months compared with the placebo. In the DEFINE (determining the efficacy and tolerability of CETP inhibition with anacetrapib) clinical study, anacetrapib increased HDL cholesterol levels by $138 \%$ and decreased LDL cholesterol levels by $36 \%$. In contrast with torcetrapib, anacetrapib had no adverse cardiovascular effects. The potential of dalcetrapib and anacetrapib in the treatment of cardiovascular diseases will be revealed by two large-scale clinical trials, the dal-OUTCOMES (efficacy and safety of dalcetrapib in patients with recent acute coronary syndrome) study and the REVEAL (randomized evaluation of the effects of anacetrapib through lipid modification, a large-scale, randomized placebo-controlled trial of the clinical effects of anacetrapib among people with established vascular disease) study. The dal-OUTCOMES study is testing whether dalcetrapib can reduce cardiovascular events and the REVEAL study is testing whether anacetrapib can reduce cardiovascular events. These reports are expected to be released by 2013 and 2017, respectively.

Keywords: dalcetrapib, anacetrapib, cholesteryl ester transfer protein (CETP), CETP inhibitor, CETP modulator, high-density lipoprotein, cardiovascular disease

\section{Introduction}

Cardiovascular disease remains the most common cause of morbidity and mortality despite the significant reduction of cardiovascular events with the use of hydroxymethylglutaryl-coenzyme A reductase inhibitors (statins) that lower lowdensity lipoprotein (LDL) cholesterol. ${ }^{1}$ A low level of high-density lipoprotein (HDL) cholesterol is another critical risk factor for cardiovascular events independent of LDL cholesterol levels, and an inverse relationship is observed between HDL cholesterol and 
the risk of cardiovascular disease..$^{2-4}$ Moreover, higher levels of HDL cholesterol are associated with reduced plaque progression and reduced frequency of cardiovascular events. ${ }^{5,6}$ Therefore, raising HDL cholesterol is considered an attractive target for cardiovascular-risk lowering strategies. However, current HDL cholesterol-elevating drugs (fibrates and niacin) have limited efficacy and undesirable side effects. ${ }^{7,8}$

Cholesteryl ester transfer protein (CETP) is a plasma glycoprotein that is bound mainly to HDL particles, primarily $\mathrm{HDL}_{3}$ subclass, and transfers cholesteryl ester (CE) and triglyceride (TG) between circulating lipoproteins. ${ }^{9}{ }^{10}$ CETP mediates the heterotypic transfer of neutral lipids (CE and TG) between HDL and apolipoprotein B (apoB)-containing lipoproteins (such as LDL and VLDL) as well as the homotypic transfer of $\mathrm{CE}$ among $\mathrm{HDL}$ subparticles $\left(\mathrm{HDL}_{3}\right.$, $\mathrm{HDL}_{2}$, and pre- $\beta \mathrm{HDL}$ ) (Figure 1). Since the net transfer of $\mathrm{CE}$ is from HDL to apoB-containing lipoproteins according to the concentration gradient, CETP is noted as an attractive target for raising HDL cholesterol. ${ }^{11-13}$ Indeed, the inhibition of CETP raises plasma HDL cholesterol levels. ${ }^{14-18}$ However, raised HDL cholesterol induced by CETP inhibition leads to an increase in cholesterol clearance via the HDL-mediated reverse cholesterol transport (RCT) pathway, which transfers excess cholesterol from the macrophages in the atherosclerotic lesions to the liver for excretion into bile. The dynamics of HDL-mediated RCT should be more important than the levels of HDL cholesterol in the bloodstream. Overly high levels of HDL cholesterol beyond the capacity of RCT may not be beneficial. Enhanced RCT and a higher turnover of HDL cholesterol may keep HDL cholesterol at appropriate levels. Dalcetrapib, a CETP modulator, and anacetrapib, a CETP inhibitor, are the most advanced agents and are in Phase III of clinical studies to reveal whether the agents are beneficial for the treatment of atherosclerosis-related diseases. ${ }^{19-22}$

\section{CETP modulator, dalcetrapib (JTT-705)}

Dalcetrapib (JTT-705) is the first small molecule that has succeeded in regulating CETP and demonstrating an antiatherogenic effect in vivo. ${ }^{23}$ Dalcetrapib is a benzenethiol derivative (Figure 2) that inhibits the CETP-mediated transfer of CE from HDL to apoB-containing lipoproteins in human plasma at an $\mathrm{IC}_{50}$ of $9 \mu \mathrm{M}$. The administration of dalcetrapib in cholesterol-fed rabbits at oral doses of $225 \mathrm{mg} / \mathrm{kg}$ /day for 6 months caused a 90\% increase in HDL cholesterol and decreased non-HDL cholesterol by $40 \%-50 \%$ compared to the control values. In the increased HDL cholesterol, $\mathrm{HDL}_{2}$ cholesterol increased by $170 \%$ and $\mathrm{HDL}_{3}$ cholesterol increased by $59 \%$. Serum apolipoprotein A-I (apoA-I), which is the primary protein constituent of the HDL particle, also increased by $78 \%$. As a result, dalcetrapib decreased the area of atherosclerotic lesions in the aortic arch by $70 \%$, providing the first evidence that the small-molecule compound has a continuous inhibitory effect on CETP activity and retards the progression of atherosclerosis.

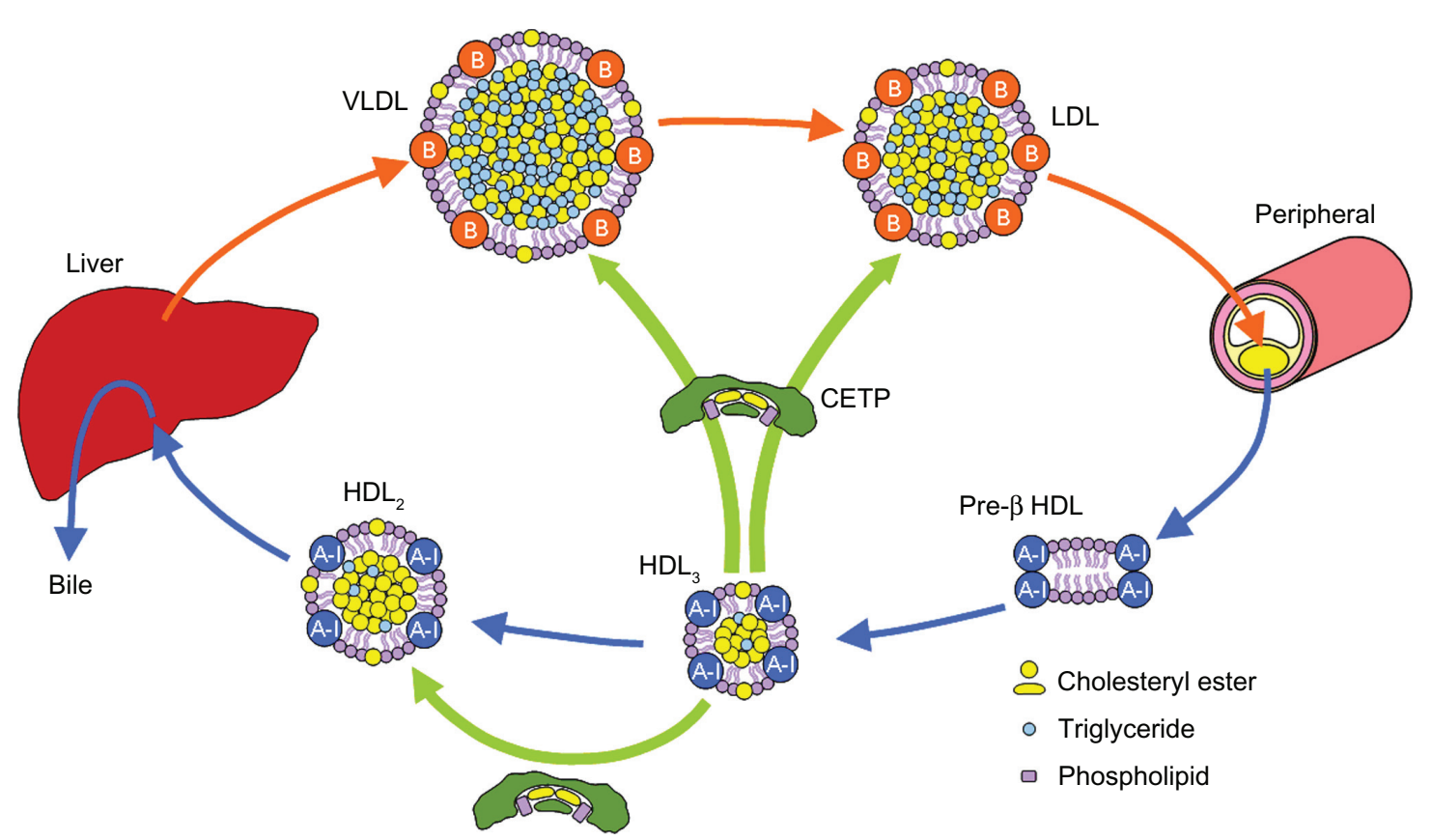

Figure I Cholesterol transport.

Abbreviations: CETP, cholesteryl ester transfer protein; HDL, high-density lipoprotein; LDL, low-density lipoprotein; VLDL, very low-density lipoprotein. 
<smiles>CCC(CC)CC1(C(=O)Nc2ccccc2SC(=O)C(C)C)CCCCC1</smiles>

Dalcetrapib (JTT-705)<smiles>CCC(CC)CC1(C(=O)Nc2ccccc2S)CCCCC1</smiles>

Thiol form of dalcetrapib

Figure 2 Structures of dalcetrapib and its thiol form.

The mechanism of action associated with dalcetrapib was examined using point mutants of recombinant human CETP. The $\mathrm{C} 13 \mathrm{~S}$ mutant, in which the cysteine at residue 13 was replaced by serine, was not inhibited by dalcetrapib, which suggests that the mechanism of action involved the formation of a disulfide bond between the thiol form of dalcetrapib and Cys 13 of CETP. The disulfide bond between the thiol form of dalcetrapib and CETP is apparently reversible because the CETP inhibition induced by dalcetrapib decreased with time. The structure of CETP was determined at 2.2-Å resolution, revealing a $60-\AA \AA-l o n g$ continuous tunnel filled with two hydrophobic CEs and plugged by an amphiphilic phosphatidylcholine at each end. ${ }^{24}$ The tunnel through the CETP - a tube with two distinct openings - allows the neutral lipid to pass through its entire length. In the through-the-tunnel model, the CETP potentially admits a neutral lipid from one opening and deposits a bound lipid from the opposite opening (Figure 3). Conformational changes are considered necessary so that the curvature of the concave surface of the CETP matches the different radius of the curvature of the lipoproteins, such as HDL, LDL, and VLDL. This model explains the CETP-mediated equimolar heteroexchange of CE and TG. The crystal structure also revealed that the Cys 13 is located on the surface of the tunnel, which indicates that dalcetrapib, which is bound to the Cys 13 of CETP, occupies part of the space for one $\mathrm{CE}$ and blocks the neutral lipid from binding or passing through the tunnel (Figure 4). The blockage caused by dalcetrapib impairs the function of CETP. Structurally, the dalcetrapib-bonded CETP should reduce its capacity of transport by $50 \%$ or more.

Interestingly, dalcetrapib inhibits the CETP-mediated heterotypic transfer of $\mathrm{CE}$ from HDL to apoB-containing
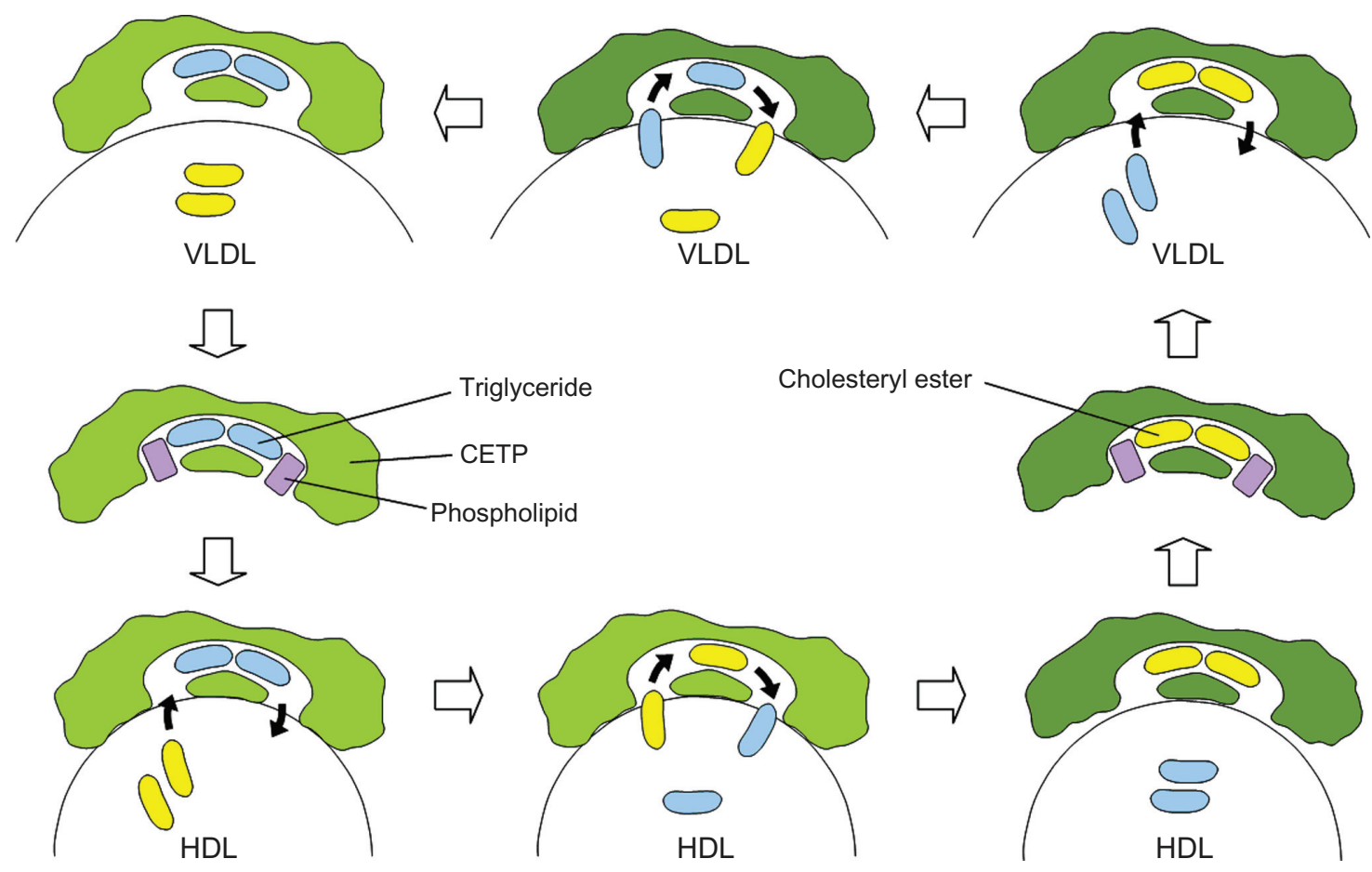

Figure 3 The through-the-tunnel model.

Abbreviations: CETP, cholesteryl ester transfer protein; HDL, high-density lipoprotein; VLDL, very low-density lipoprotein. 


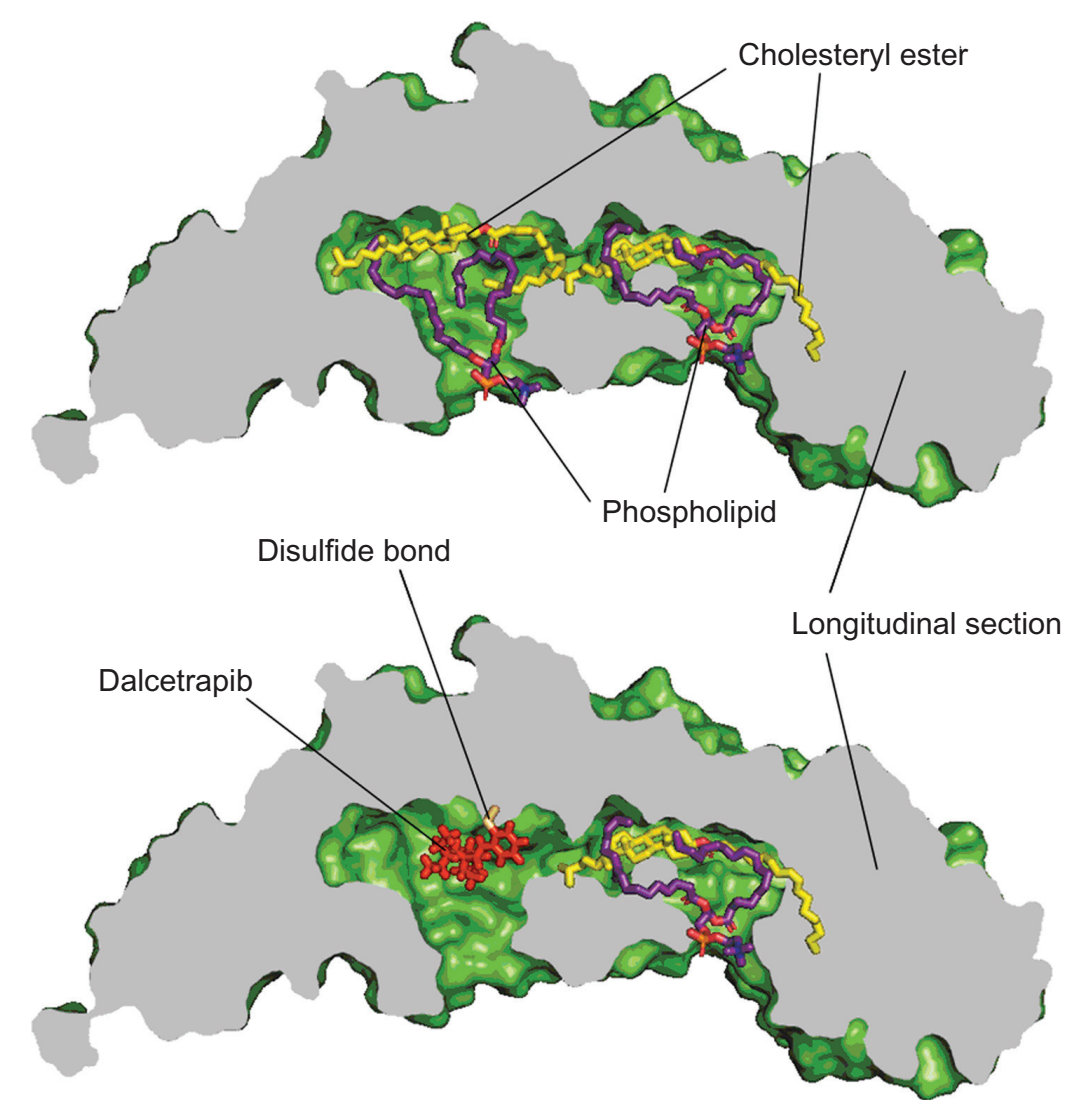

Figure 4 Bound lipids and dalcetrapib in the tunnel of CETP.

Abbreviation: CETP, cholesteryl ester transfer protein.

lipoproteins without inhibiting the CETP-mediated homotypic transfer of CE from $\mathrm{HDL}_{3}$ to $\mathrm{HDL}_{2}$ (Figure 5). ${ }^{25}$ The CETP-mediated homotypic CE transfer generates larger $\mathrm{HDL}_{2}$ and smaller pre- $\beta$ HDL from $\mathrm{HDL}_{3}{ }^{25}$ Since this process transfers CE along the RCT pathway, the partial CETP inhibition caused by dalcetrapib is considered more beneficial for CE clearance than complete CETP inhibition. In hamsters injected with ${ }^{3} \mathrm{H}$-labeled cholesterol-containing autologous macrophages, dalcetrapib (100 mg twice daily for 7 days) increased plasma HDL ${ }^{3} \mathrm{H}$-labeled cholesterol as well as the fecal elimination of ${ }^{3} \mathrm{H}$-labeled neutral sterols and ${ }^{3} \mathrm{H}$-labeled bile acids. ${ }^{25}$ The results indicate that dalcetrapib increases RCT and CE clearance.

Although the mechanism leading to partial CETP inhibition by dalcetrapib has not been elucidated, the function of dalcetrapib-bonded CETP is likely the key. The dalcetrapib-bonded CETP potentially holds one CE in the tunnel and transfers the $\mathrm{CE}$ from $\mathrm{HDL}_{3}$ to $\mathrm{HDL}_{2}$ differently to the through-the-tunnel model (Figure 6). The transfer is against the concentration gradient of $\mathrm{CE}$. The reason why the dalcetrapib-bonded CETP can discriminate between the heterotypic transfer and the homotypic transfer may be because the dalcetrapib-bonded CETP cannot conform by attaching to the surface of apoB-containing lipoproteins, but it can conform by attaching to the surface of HDL particles. Dalcetrapib is considered a CETP modulator because of its unique effects on CETP functions. ${ }^{25}$

In the dal-VESSEL (dalcetrapib Phase IIb endothelial function) study, 476 patients with coronary heart disease or cardiovascular risk equivalents were randomized to $600 \mathrm{mg} /$ day of dalcetrapib or placebo in addition to their existing treatments for 36 weeks. ${ }^{26}$ Dacetrapib reduced CETP activity by $50 \%$ and increased HDL cholesterol levels by $31 \%$ without changing LDL cholesterol levels. In the dal-VESSEL study, dalcetrapib did not impair nitric-oxide-dependent endothelial functions, change markers of inflammation and oxidative stress, or increase blood pressure. The dal-PLAQUE (safety and efficacy of dalcetrapib on atherosclerotic disease using novel non-invasive multimodality imaging) study provided data on the effects of dalcetrapib on structural and functional markers for atherogenesis. In this study, 130 patients with coronary heart disease or cardiovascular risk equivalents were randomly assigned to dalcetrapib $600 \mathrm{mg} /$ day or placebo in addition to statin or other LDL cholesterol-lowering drug treatment for 24 months. ${ }^{19}$ 


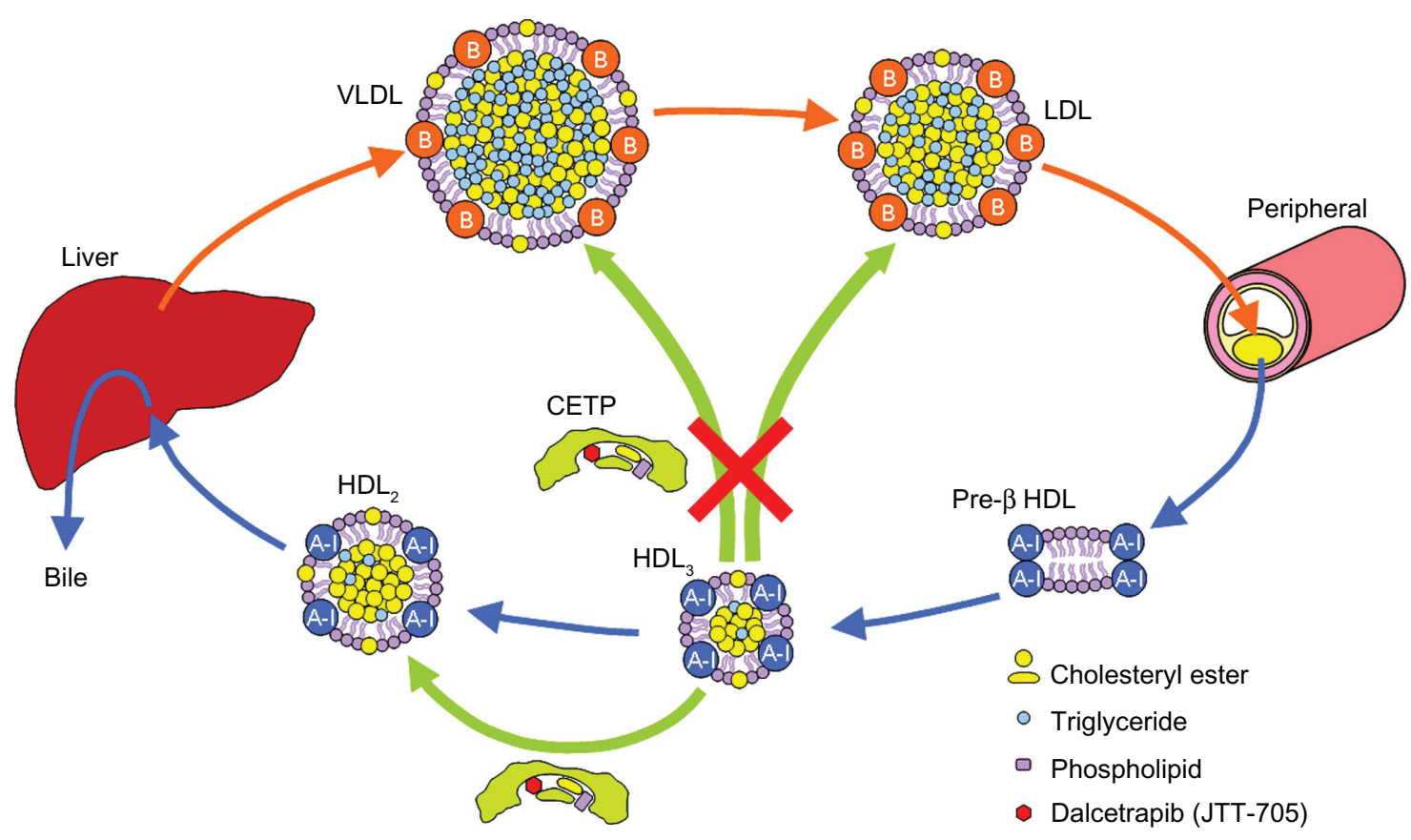

Figure 5 The effects of dalcetrapib on CETP-mediated cholesterol transport.

Abbreviations: CETP, cholesteryl ester transfer protein; HDL, high-density lipoprotein; LDL, low-density lipoprotein; VLDL, very low-density lipoprotein.

Magnetic resonance imaging (MRI) was used to analyze the vessel wall structure and ${ }^{18} \mathrm{~F}$-labeled fluorodeoxyglucose $\left({ }^{18} \mathrm{~F}-\mathrm{FDG}\right)$ positron emission tomography (PET)/computed tomography (CT) to measure vessel wall inflammation. HDL cholesterol concentrations in the dalcetrapib group increased by $30.9 \%$ from baseline without changing LDL cholesterol and TG concentrations. Dalcetrapib did not increase inflammation in the vessel wall over 6 months compared with the placebo. Carotid vessel analysis of the
${ }^{18} \mathrm{~F}-\mathrm{FDG}-\mathrm{PET} / \mathrm{CT}$ data showed a $7 \%$ reduction in vascular inflammation over 6 months in the dalcetrapib group relative to the placebo group. Moreover, dalcetrapib did not increase plaque progression over 24 months compared with the placebo. MRI-driven change in the total vessel area was reduced in the dalcetrapib group compared with the placebo group, and the absolute change from baseline relative to placebo was $-4.01 \mathrm{~mm}^{2}$. This trial suggested the possible beneficial vascular effects of dalcetrapib, but
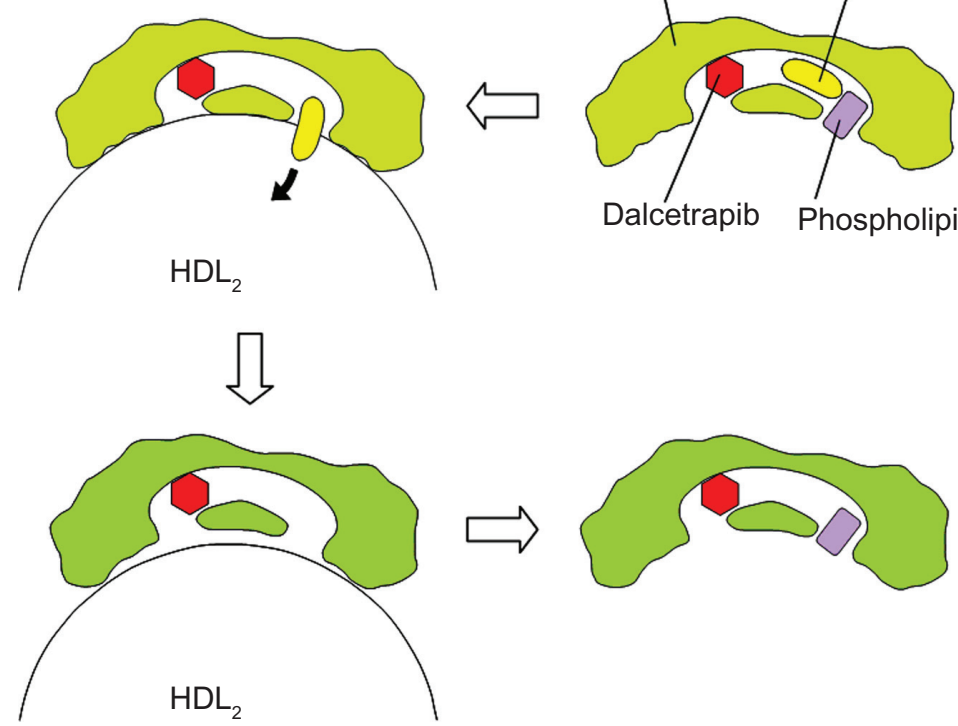
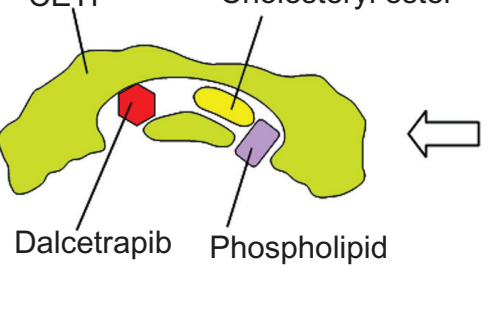

(1)
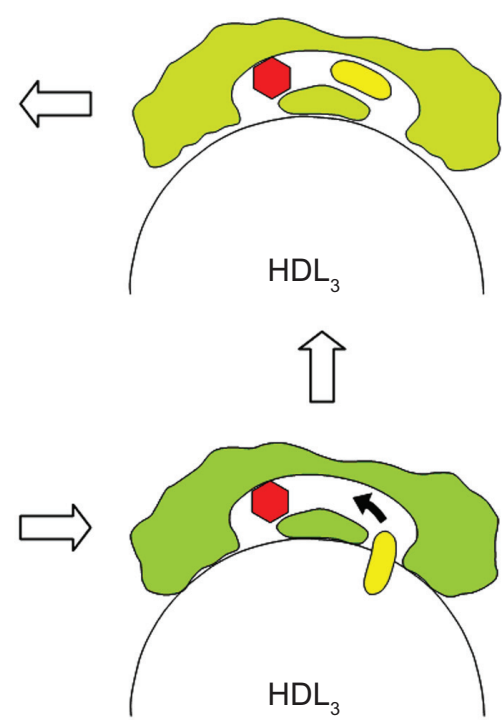

Figure 6 Hypothetic homotypic transfer mediated by dalcetrapib-bonded CETP.

Abbreviations: CETP, cholesteryl ester transfer protein; HDL, high-density lipoprotein. 
the crucial question is whether the beneficial effects of dalcetrapib will result in reduced cardiovascular events. The dal-OUTCOMES (efficacy and safety of dalcetrapib in patients with recent acute coronary syndrome) study, which includes 15,600 patients, is currently testing the addition of dalcetrapib to standard medical therapy for the reduction of cardiovascular events. Phase III of the study will be completed by $2013 .^{27}$

\section{A series of 3,5-bis(trifluoromethyl) phenyl derivatives as CETP inhibitors \\ Torcetrapib}

Torcetrapib, a 3,5-bis(trifluoromethyl)phenyl derivative, was the most advanced CETP inhibitor until its development was terminated due to its adverse effects. The ILLUMINATE (investigation of lipid-level management using coronary ultrasound to assess reduction of atherosclerosis by CETP inhibition and HDL elevation) study was prematurely terminated because of an increased cardiovascular event rate in patients receiving the CETP inhibitor, torcetrapib. In Phase III of the study, 15,067 patients at high risk for cardiovascular disease were randomly assigned to receive either $60 \mathrm{mg}$ of torcetrapib plus atorvastatin, or placebo plus atorvastatin. Torcetrapib caused a $72.1 \%$ increase in HDL cholesterol and a $24.9 \%$ decrease in LDL cholesterol. Despite the favorable lipid changes in the torcetrapib group, the rate of major cardiovascular events increased by $25 \%$ and the rate of death from cardiovascular causes increased by $40 \%{ }^{28}$ Torcetrapib was also associated with an increase of $5.4 \mathrm{mmHg}$ in systolic blood pressure. Currently, adverse events caused by torcerapib are considered to be molecule-specific and are not to relate to the mechanism of CETP inhibition. The RADIANCE (a pooled analysis of the rating atherosclerotic disease change by imaging with a new CETP inhibitor) and the ILLUMINATE studies indicated a relationship between increased blood pressure and thickening carotid vessel walls, as well as between renin-angiotensin-aldosterone system (RAAS) activation and risk of death. ${ }^{28-32}$ In contrast, it has been confirmed that other CETP inhibitors and dalcetrapib have no effect on the upregulation of genes, encoding components of the RAAS, increased concentration of mineralocorticoid hormones, or raised blood pressure. ${ }^{33,34}$

After finding a tetrazole derivative (Figure 7), which revealed that the carbamate moiety could be replaced with an amino-tetrazole ring and the tetrahydropyridine ring could be opened to acyclic structures, 3,5-bis(trifluoromethyl)phenyl derivatives lacking torcetrapib-specific adverse effects, such as anacetrapib and evacetrapib, were derived from torcerapib. ${ }^{35}$ Figure 7 presents the main structural transition of the torcetrapib series. Among the torcetrapib series of CETP inhibitors, the most advanced anacetrapib is in Phase III of a study and the second evacetrapib is in Phase II of a study. ${ }^{18,20,36}$

\section{Anacetrapib}

In contrast with dalcetrapib, anacetrapib inhibits the heterotypic $\mathrm{CE}$ transfer from HDL to LDL and the homotypic $\mathrm{CE}$
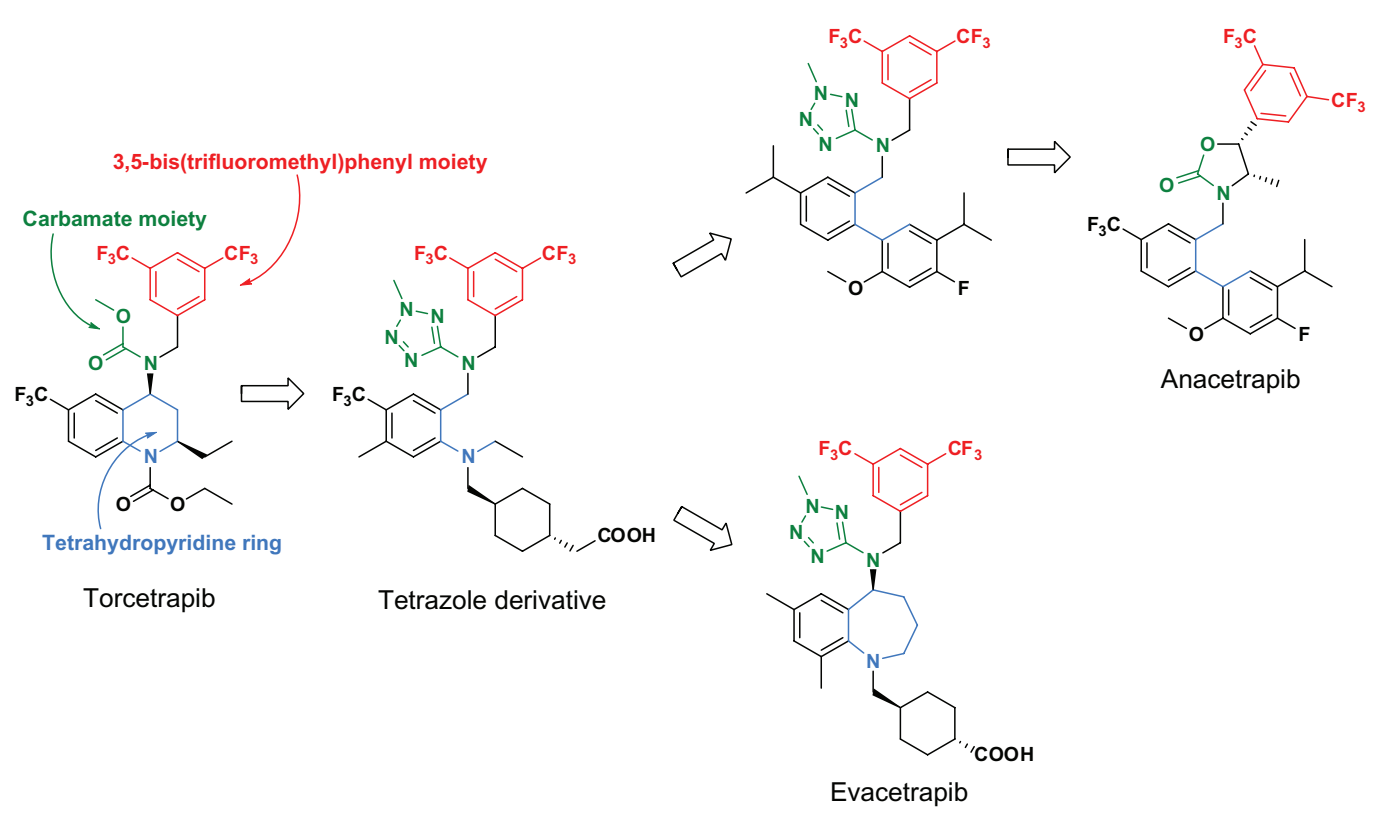

Figure 7 Structural transition of 3,5-bis(trifluoromethy)phenyl derivatives as CETP inhibitors. Abbreviation: CETP, cholesteryl ester transfer protein. 
transfer from $\mathrm{HDL}_{3}$ to $\mathrm{HDL}_{2}$ (Figure 8). Although the exact mechanism of CETP inhibition by the torcerapib series of compounds including anacetrapib has not been elucidated, the torcetrapib series of CETP inhibitors bind specifically to CETP with 1:1 stoichiometry and block all of the major transfer functions of plasma CETP by inducing a nonproductive complex between the transfer protein and HDL. ${ }^{37}$ Anacetrapib demonstrated dose-dependent inhibition of pre- $\beta$ HDL formation in vitro, and did not increase the fecal elimination of ${ }^{3} \mathrm{H}$-labeled neutral sterols and ${ }^{3} \mathrm{H}$-labeled bile acids in hamsters injected with ${ }^{3} \mathrm{H}$-labeled cholesterolcontaining autogous macrophages, despite increasing plasma HDL ${ }^{3} \mathrm{H}$-labeled cholesterol. ${ }^{25}$ This indicates that anacetrapib could not increase HDL-mediated RCT in hamsters despite a marked increase in plasma HDL cholesterol. Raised HDL cholesterol can be expected to enhance HDL-mediated RCT, but the inhibitory effect of anacetrapib on CETP-mediated homotypic CE transfer may block this enhancement. CETPmediated homotypic $\mathrm{CE}$ transfer may be more important for HDL-mediated RCT than expected. However, the clinical relevance of the results is unknown.

In contrast with torcetrapib, anacetrapib did not result in raised blood pressure in the Phase I or II studies and does not increase aldosterone synthesis in adrenal cortical cells..$^{16,17,33,38}$ The safety of anacetrapib was further studied in the DEFINE (determining the efficacy and tolerability of CETP inhibition with anacetrapib) trial. ${ }^{20}$ In the DEFINE study, 1623 patients with coronary heart disease or who were at high risk for coronary heart disease were randomized to $100 \mathrm{mg} /$ day of anacetrapib or placebo in addition to statin treatment with or without other lipid-modifying therapy for 18 months. In this study, anacetrapib increased HDL cholesterol levels by $138 \%$ and decreased LDL cholesterol levels by $36 \%$. The study confirmed that anacetrapib had no effect on electrolytes, aldosterone levels, or blood pressure. The adverse cardiovascular event levels did not differ between the anacetrapib and placebo groups.

The REVEAL (randomized evaluation of the effects of anacetrapib through lipid modification, a large-scale, randomized placebo-controlled trial of the clinical effects of anacetrapib among people with established vascular disease) cardiovascular outcome study, which includes 30,000 patients, is currently testing whether anacetrapib will reduce the incidence of major coronary events (coronary mortality, myocardial infarction, and coronary revascularization) in patients with a history of cardiovascular disease who are undergoing statin therapy to lower LDL cholesterol. ${ }^{36}$ This Phase III study is expected to be completed by 2017 .

\section{Evacetrapib}

Another CETP inhibitor, evacetrapib, showed a marked increase in HDL cholesterol and a decrease in LDL cholesterol with no change in blood pressure or aldosterone levels. These results are derived from a 12-week Phase II study that included 398 patients with elevated LDL cholesterol or low LDL cholesterol levels. A daily dose of $500 \mathrm{mg}$ of evacetrapib

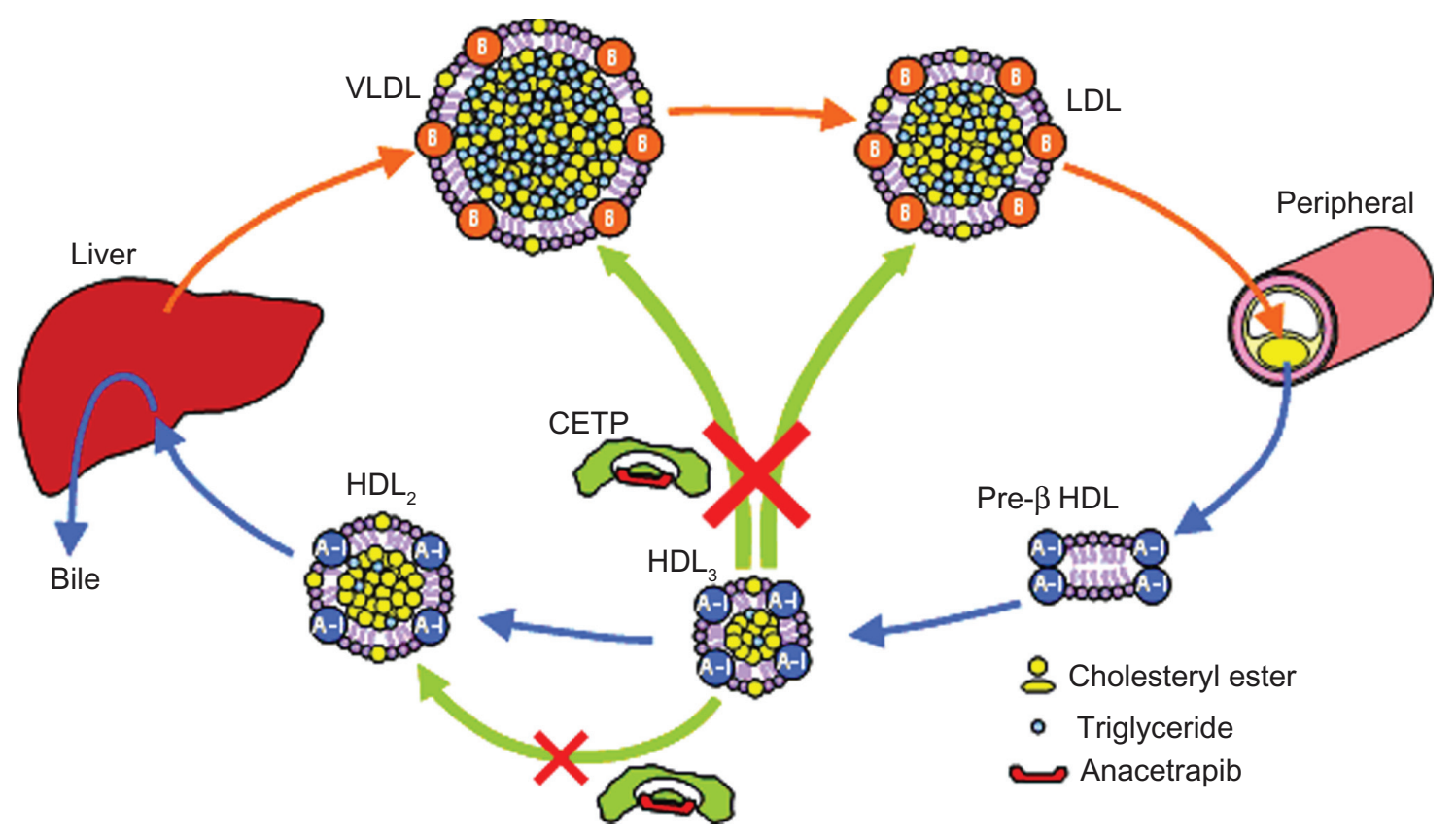

Figure 8 The effects of anacetrapib on CETP-mediated cholesterol transport.

Abbreviations: CETP, cholesteryl ester transfer protein; HDL, high-density lipoprotein; LDL, low-density lipoprotein; VLDL, very low-density lipoprotein. 
Table I CETP modulator and inhibitors

\begin{tabular}{|c|c|c|c|c|}
\hline & Dalcetrapib & Torcetrapib & Anacetrapib & Evacetrapib \\
\hline Chemical class & Benzenethiol & 3,5-bis $\left(\mathrm{CF}_{3}\right)$ phenyl & 3,5-bis $\left(\mathrm{CF}_{3}\right)$ phenyl & 3,5-bis $\left(\mathrm{CF}_{3}\right)$ phenyl \\
\hline Effect on CETP & $\begin{array}{l}\text { Modulation } \\
\text { (selective inhibition) }\end{array}$ & Complete inhibition & Complete inhibition & No data \\
\hline Heterotypic CE transfer & Block & Block & Block & No data \\
\hline Homotypic CE transfer & No effect & Block & Block & No data \\
\hline $\begin{array}{l}\text { RCT (fecal elimination of } \\
\text { neutral sterols and bile acids) }\end{array}$ & Increase & Slight increase & No change & No data \\
\hline Clinical stage & Phase III & Termination & Phase III & Phase II \\
\hline \multicolumn{5}{|l|}{ Clinical data } \\
\hline HDL increase & $31 \%$ & $72 \%$ & $138 \%$ & $132 \%$ \\
\hline LDL decrease & No change & $25 \%$ & $36 \%$ & $40 \%$ \\
\hline Aldosterone levels & No change & Increase & No change & No change \\
\hline Blood pressure & No change & Increase & No change & No change \\
\hline Vascular inflammation & Reduction (PET/CT) & No data & No data & No data \\
\hline Plaque progression & Reduction (MRI) & No data & No data & No data \\
\hline Safety & Safe & $\begin{array}{l}\text { Increased cardiovascular } \\
\text { events and death }\end{array}$ & Safe & Safe \\
\hline
\end{tabular}

Abbreviations: $\mathrm{CF}_{3}$, trifluoromethyl; CETP, cholesteryl ester transfer protein; CE, cholesteryl ester; RCT, reverse cholesterol transport; HDL, high-density lipoprotein; LDL, low-density lipoprotein; PET, positron emission tomography; CT, computed tomography; MRI, magnetic resonance imaging.

as monotherapy increased HDL cholesterol levels by $132 \%$ and decreased LDL cholesterol levels by $40 \%{ }^{18}$

\section{Conclusion}

Anacetrapib belongs to the torcetrapib series of CETP inhibitors, but has no adverse cardiovascular effects in contrast with torcetrapib. Anacetrapib blocks the transfer functions of CETP and achieves a favorable plasma-lipids profile as well as a marked increase in HDL cholesterol and decrease in LDL cholesterol. Unexpectedly, anacetrapib does not increase RCT despite markedly increasing HDL cholesterol in vivo using a hamster model, although the clinical relevance of the result is unknown. Even if increased HDL cholesterol induced by anacerapib does not increase cholesterol clearance via the HDL-mediated RCT pathway, the simultaneous decrease of LDL cholesterol induced by anacetrapib can be expected to improve the cardiovascular condition.

Dalcetrapib provided a relatively smaller increase in HDL cholesterol than anacetrapib did. This may be due to a higher turnover of HDL cholesterol, because the CETP modulator, dalcetrapib, does not inhibit CETP-mediated homotypic CE transfer and increases HDL-mediated RCT. It is worth noting the dynamics of cholesterol clearance rather than the levels of HDL cholesterol in the bloodstream. Abnormally high levels of HDL cholesterol could indicate a failure to enhance RCT and cholesterol clearance. Despite the smaller increase in plasma HDL cholesterol levels, dalcetrapib showed a reduction in vascular inflammation and structural vascular changes (plaque progression) in clinical studies.
The CETP modulator, dalcetrapib, and the CETP inhibitor, anacetrapib, are currently in Phase III trials to test their effects on cardiovascular outcomes. Dalcetrapib can reveal the role of HDL cholesterol in reducing cardiovascular events, because dalcetrapib increases HDL cholesterol without lowering LDL cholesterol. In contrast, the simultaneous decrease of LDL cholesterol by anacetrapib complicates the interpretation of the role of HDL cholesterol. However, anacetrapib can reveal the role of CETP in cardiovascular events.

\section{Disclosure}

The author is the coinventor of dalcetrapib, and an employee of JT Inc. JT Inc licensed-out JTT-705 (dalcetrapib) to F Hoffmann-La Roche Ltd.

\section{References}

1. Bays H, Stein EA. Pharmacotherapy for dyslipidemia-current therapies and future agents. Expert Opin Pharmacother. 2003;4:1901-1938.

2. Gordon T, Castelli WP, Hjortland MC, Kannel WB, Dawber TR. High density lipoprotein as a protective factor against coronary heart disease. The Framingham Study. Am J Med. 1977;62:707-714.

3. Jafri H, Alsheikh-Ali AA, Karas RH. Meta-analysis: statin therapy does not alter the association between low levels of high-density lipoprotein cholesterol and increased cardiovascular risk. Ann Intern Med. 2010;153: 800-808.

4. Arsenault BJ, Barter P, DeMicco DA, et al. Prediction of cardiovascular events in statin-treated stable coronary patients by lipid and nonlipid biomarkers. J Am Coll Cardiol. 2011;57:63-69.

5. Johnsen SH, Mathiesen EB, Fosse E, et al. Elevated high-density lipoprotein cholesterol levels are protective against plaque progression: a follow-up study of 1952 persons with carotid atherosclerosis the Tromsø study. Circulation. 2005;112:498-504. 
6. Wei L, Murphy MJ, MacDonald TM. Impact on cardiovascular events of increasing high density lipoprotein cholesterol with and without lipid lowering drugs. Heart. 2006;92:746-751.

7. Rubins HB, Robins SJ, Collins D. et al. Gemfibrozil for the secondary prevention of coronary heart disease in men with low levels of highdensity lipoprotein cholesterol. N Engl J Med. 1999;341:410-418.

8. Shepherd J, Betteridge J, Van Gaal L, et al. Nicotinic acid in the management of dyslipidaemia associated with diabetes and metabolic syndrome: a position paper developed by a European Consensus Panel. Curr Med Res Opin. 2005;21:665-682.

9. Tall AR. Plasma cholesteryl ester transfer protein. J Lipid Res.1993;34: 1255-1274.

10. Marcel YL, McPherson M, Hogue H, et al. Distribution and concentration of cholesteryl ester transfer protein in plasma of normolipemic subjects. J Clin Invest. 1990;85:10-17.

11. Ha YC, Gorjatschko L, Barter PJ. Changes in the density distribution of pig high density lipoproteins during incubation in vitro. Influence of esterified cholesterol transfer activity. Atherosclerosis 1983;48: 253-263.

12. Paromov VM, Morton RE. Lipid transfer inhibitor protein defines the participation of high-density lipoprotein subfractions in lipid transfer reactions mediated by cholesterol ester transfer protein (CETP). J Biol Chem. 2003;278:40859-40866.

13. Barter PJ, Brewer HB Jr, Chapman J, et al. Cholesteryl ester transfer protein. A novel target for raising HDL and inhibiting atherosclerosis. Arterioscler Thromb Vas Biol. 2003;23:160-167.

14. De Grooth GJ, Kuivenhoven JA, Stalenhoef AF, et al. Efficacy and safety of a novel cholesteryl ester transfer protein inhibitor, JTT-705, in humans: a randomized phase II dose-response study. Circulation 2002;105(21):2159-2165.

15. Kuivenhoven JA, De Grooth GJ, Kawamura H, et al. Effectiveness of inhibition of cholesteryl ester transfer protein by JTT-705 in combination with pravastatin in type II dyslipidemia. Am J Cardiol. 2005;95:1085-1088.

16. Krishna R, Anderson MS, Bergman AJ, et al. Effect of the cholesteryl ester transfer protein inhibitor, anacetrapib, on lipoproteins in patients with dyslipidaemia and on 24-h ambulatory blood pressure in healthy individuals: two double-blind, randomized placebo-controlled phase I studies. Lancet. 2007;370:1907-1914.

17. Bloomfield D, Carlson GL, Sapre A, et al. Efficacy and safety of the cholesteryl ester transfer protein inhibitor anacetrapib as monotherapy and coadministered with atorvastatin in dyslipidemic patients. Am Heart J. 2008;157(2):352-360.

18. Nicholls SJ, Brewer HB, Kastelein JJP, et al. Effects of the CETP inhibitor evacetrapib administered as monotherapy or in combination with statin on HDL and LDL cholesterol. A randomized controlled trial. JAMA. 2011;306(19):2099-2109.

19. Fayad ZA, Mani V, Woodward M, et al. Safety and efficacy of dalcetrapib on atherosclerotic disease using novel non-invasive multimodality imaging (dal-PLAQUE): a randomized clinical trial. Lancet. 2011;378:1547-1559.

20. Cannon CP, Shah S, Dansky HM, et al. Safety of anacetrapib in patients with or at high risk for coronary heart disease. New Engl J Med. 2010;363(25):2406-2415.

21. Davidson MH. Update on CETP inhibition. J Clin Lipidology. 2010; 4(5):394-398.
22. Miyares MA. Anacetrapib and Dalcetrapib: Two novel cholesteryl ester transfer protein inhibitors. Ann Pharmacother. 2011;45(1):84-94.

23. Okamoto H, Yonemori F, Wakitani K, Minowa T, Maeda K, Shinkai H. A cholesteryl ester transfer protein inhibitor attenuates atherosclerosis in rabbits. Nature. 2000;406(6792):203-207.

24. Qui X, Mistry A, Ammirati MJ, et al. Crystal structure of cholesteryl ester transfer protein reveals a long tunnel and four bound lipid molecules. Nat Struct Mol Biol. 2007;14(2):106-113.

25. Niesor EJ, Magg C, Ogawa N, et al. Modulating cholesteryl ester transfer protein activity maintains efficient pre- $\beta$-HDL formation and increases reverse cholesterol transport. J Lipid Res. 2010;51:3443-3454.

26. Lüscher T. Dalcetrapib passed test in dal-VESSEL: Raises HDL cholesterol but not blood pressure. European Society of Cardiology Congress; August 29, 2011. Paris.

27. Schwartz GG, Olsson AG, Ballantyne CM, et al. Rationale and design of the dal-OUTCOMES trial: efficacy and safety of dalcetrapib in patients with recent acute coronary syndrome. Am Heart J. 2009;158: 896-901.

28. Barter PJ, Caulfield M, Eriksson M, el al. Effects of torcetrapib in patients at high risk for coronary events. $N$ Engl J Med. 2007;357: 2109-2122.

29. Rader DJ. Illuminating HDL - Is it still a viable therapeutic target? N Engl J Med. 2007;357:2180-2183.

30. Vergeer M, Bots ML, van Leuven SI, et al. Cholesteryl ester transfer protein inhibitor torcetrapib and off-target toxicity. A pooled analysis of the rating atherosclerotic disease change by imaging with a new CETP inhibitor (RADIANCE) trials. Circulation. 2008;118(25):2515-2522.

31. Kastelein JJ, van Leuven SI, Burgess L, et al. Effect of torcetrapib on carotid atherosclerosis in familial hypercholesterolemia. NEngl J Med. 2007;356:1620-1630.

32. Bots ML, Visseren FL, Evans GW, et al. Torcetrapib and carotid intima-media thickness in mixed dyslipidaemia (RADIANCE 2 study): a randomised, double-blind trial. Lancet. 2007;370:153-160.

33. Hu X, Dietz JD, Xia C, et al. Torcetrapib induces aldosterone and cortisol production by an intracellular calcium-mediated mechanism independently of cholesteryl ester transfer protein inhibition. Endocrinology. 2009;150:2211-2219.

34. Stroes ES, Kastelein JJ, Benardeau A, et al. Dalcetrapib: no off-target toxicity on blood pressure or on genes related to the renin-angiotensinaldosterone system in rats. Br J Pharmacol. 2009;158:1763-1770.

35. Shinkai, H. Cholesteryl ester transfer protein inhibitors as high-density lipoprotein raising agents. Expert Opin Ther Patents. 2009;19(9): $1229-1237$.

36. Gutstein DE, Krishna R, Johns D, et al. Anacetrapib, a novel CETP inhibitor: pursuing a new approach to cardiovascular risk reduction. Clin Pharmacol Ther. 2012;91(1):109-122.

37. Clark RW, Ruggeri RB, Cunningham D, et al. Description of the torcetrapib series of cholesteryl ester transfer protein inhibitors, including mechanism of action. J Lipid Res. 2006;47:536-552.

38. Forrest MJ, Bloomfield D, Briscoe RJ, et al. Torcetrapib-induced blood pressure elevation is independent of cholesteryl ester transfer protein inhibition and is accompanied by an increase in circulating aldosterone levels. Br J Pharmacol. 2008;154:1465-1473.
Vascular Health and Risk Management

\section{Publish your work in this journal}

Vascular Health and Risk Management is an international, peerreviewed journal of therapeutics and risk management, focusing on concise rapid reporting of clinical studies on the processes involved in the maintenance of vascular health; the monitoring, prevention and treatment of vascular disease and its sequelae; and the involvement of

\section{Dovepress}

metabolic disorders, particularly diabetes. This journal is indexed on PubMed Central and MedLine. The manuscript management system is completely online and includes a very quick and fair peer-review system, which is all easy to use. Visit http://www.dovepress.com/ testimonials.php to read real quotes from published authors. 